\title{
Risk for Future Diabetes among Individuals with High-normal Glycemia at 40 Years of Age
}

\author{
Yusuke Kabeya ${ }^{1}$, Akira Shimada ${ }^{1}$, Fumihiro Yamasawa ${ }^{2}$, Masuomi Tomita ${ }^{1}$, \\ Takeshi Katsuki ${ }^{1}$, Yoichi Oikawa ${ }^{1}$ and Yoshihito Atsumi ${ }^{1}$
}

\begin{abstract}
Objective The present study investigated the risk for future diabetes among individuals with high-normal glycemia (fasting plasma glucose (FPG) of $100-109 \mathrm{mg} / \mathrm{dL}$ ) in an early middle-aged population.

Methods We retrospectively observed a workplace cohort all aged 40 and followed the incidence of diabetes according to the FPG levels at baseline. A total of 901 non-diabetic males were included in the analysis. The 10-year cumulative incidence of diabetes was calculated. The hazard ratios of developing diabetes were calculated using a Cox proportional hazards regression.

Results The proportions of those with high-normal glycemia and impaired fasting glucose (IFG) (FPG of $110-125 \mathrm{mg} / \mathrm{dL}$ ) at baseline were $21.5 \%$ and $4.7 \%$. The 10-year cumulative incidence of diabetes was $14.7 \%$ and $48.9 \%$, respectively, in these individuals. After adjustment for possible confounders, the hazard ratios of developing diabetes among individuals with high-normal glycemia and IFG were 5.2 (95\% CI=2.4-11.2) and $21.3(95 \% \mathrm{CI}=9.2-49.5)$ relative to those with an FPG of $<90 \mathrm{mg} / \mathrm{dL}$.

Conclusion High-normal glycemia is a risk for future diabetes even in the relatively young and healthy workplace population. Although the relative risk is much higher in those with IFG, the absolute number of incident diabetes developing from those with high-normal glycemia seems to be considerable given the prevalence of this condition.
\end{abstract}

Key words: fasting plasma glucose, high-normal glycemia, impaired fasting glucose, risk for future diabetes

(Intern Med 51: 2703-2708, 2012)

(DOI: 10.2169/internalmedicine.51.7926)

\section{Introduction}

The definition of impaired fasting glucose (IFG) is not consistent worldwide. According to the American Diabetes Association (ADA) criterion, IFG is defined as fasting plasma glucose (FPG) levels of 100 to $125 \mathrm{mg} / \mathrm{dL}$, whose threshold was lowered in 2003 for a better prediction of future diabetes (1). On the other hand, other organizations, including the European Diabetes Epidemiology Group and the Japan Diabetes Society (JDS) retain the original diagnostic range for IFG at FPG of 110 to $125 \mathrm{mg} / \mathrm{dL}(2,3)$. The risk for future diabetes among those with an FPG of 100 to 109 $\mathrm{mg} / \mathrm{dL}$, who were categorized in different ways across organizations, remains controversial. Several population-based studies from different ethnic groups have reported that FPG levels of 100 to $109 \mathrm{mg} / \mathrm{dL}$ are associated with an increased risk for future diabetes (4-13). However, most studies were performed among older adults. It therefore remains unclear whether or not the evidence holds true for the early middleaged population, since aging is a potent risk factor for diabetes and can modify the association between the FPG levels and the risk for future diabetes.

Recently, Japan has implemented an annual special health screening (tokutei kenshin) and health counseling (tokutei hoken shidou) system. Under this system, everyone aged 40 years old or older is required to undergo an annual special health checkup focusing on metabolic syndrome. If they are diagnosed as being at high-risk for metabolic syndrome, health guidance regarding lifestyle modification is provided (14). As a result of the implementation of this system, an increased number of people are being found to have an

${ }^{1}$ Department of Internal Medicine, Saiseikai Central Hospital, Japan and ${ }^{2}$ Marubeni Health Promotion Center, Marubeni Corporation, Japan Received for publication April 10, 2012; Accepted for publication June 27, 2012

Correspondence to Dr. Yusuke Kabeya, ykabeyan@yahoo.co.jp 
FPG of 100 to $109 \mathrm{mg} / \mathrm{dL}$ at the age of 40 . According to the JDS, these people are categorized as having "highnormal" glycemia (15). However, a practical estimate of developing diabetes among those with high-normal glycemia in the early middle-aged population has not been provided yet. There is a high demand for a new study estimating the incidence and the risk for developing diabetes among early middle-aged individuals with high-normal glycemia.

In the present study (the Tokyo Businessman Study), we retrospectively observed one Japanese workplace cohort, all who were 40 years of age, and followed the incidence of diabetes in this population for more than 10 years. We next examined whether or not those with high-normal glycemia at 40 years of age are at an increased risk for future diabetes.

\section{Materials and Methods}

The data from the annual health checkup program conducted by Marubeni Corporation, which is one of the largest trading companies in Japan, from October 1989 to June 2011 were obtained. The data included information on the results of the Marubeni Corporation employees' annual health checkups. Males who underwent the medical checkup at 40 years of age between October 1989 and March 2000 were selected from the data set. A total of 937 individuals were included in the cohort. Of these 937 individuals, we excluded 26 individuals who had diabetes (FPG levels $\geq 126$ $\mathrm{mg} / \mathrm{dL}$ or treating diabetes) and 10 individuals with missing data at baseline. Finally, 901 non-diabetic individuals who were all 40 years of age at baseline were included in the present study.

The cohort was categorized into four groups according to the FPG level at baseline ( $<90 \mathrm{mg} / \mathrm{dL}, 90-99 \mathrm{mg} / \mathrm{dL}, 100-$ $109 \mathrm{mg} / \mathrm{dL}$, or $110-125 \mathrm{mg} / \mathrm{dL})$. The follow-up for incident diabetes was based on the annual health checkup data. Follow-up began on the date of the health examination at the age of 40. The data in the present study were collected by June 2011. The follow-up was completed at the last examination date or the date of a diagnosis of diabetes, whichever came first. The endpoint was the development of diabetes, which was defined as self-reported diabetes and/or an FPG of $126 \mathrm{mg} / \mathrm{dL}$ or higher.

The study protocol followed the Japanese Government's ethical guidelines for epidemiological research. It was reviewed and approved by the ethics committee of Saiseikai Central Hospital.

\section{Statistical analysis}

The baseline characteristics of the patients are shown after they were stratified into the four categories based on the FPG levels. The differences across the FPG categories were examined using a one-way analysis of variance (ANOVA). Multiple comparisons were conducted using Scheffe's test. The frequency of incident diabetes, person-years and the incidence rate of developing diabetes were calculated. The 10- year cumulative incidence of diabetes was calculated using the Kaplan-Meier method. Kaplan-Meier curves comparing the cumulative incidence are shown for up to 15 years of follow-up. The log-rank test was used to examine the differences in the incidence of diabetes across FPG categories. Hazard ratios (HRs) of developing diabetes were calculated using a Cox proportional hazards regression analysis with the follow-up time as a dependent time variable.

First, a univariate model was generated that included the body mass index (BMI), systolic blood pressure, diastolic blood pressure, total cholesterol, high-density lipoprotein (HDL) cholesterol, and triglycerides. All variables except the HDL cholesterol were proven to have a statistical significance of $<0.10$. Then, these variables were fitted in a multivariate model with the categorical FPG variable. The proportional hazard assumption of the multivariate model was confirmed by Schoenfeld's global test, which produced $\mathrm{p}>$ 0.05 . Population-attributable fractions (PAFs) for incident diabetes were calculated as $1-1 / \Sigma_{i=0}^{k} p_{i}\left(R R_{i}\right)(16)$, where $\mathrm{p}_{\mathrm{i}}$ refers to the proportion of each FPG category in the study population and $R R_{i}$ refers to the relative risk of incident diabetes when comparing each FPG category with the FPG category of $<90 \mathrm{mg} / \mathrm{dL}$. Regarding the relative risk of each FPG category, the multiple-adjusted hazard ratio was used in the calculation. All analyses were performed using the STATA software program (version 11; StataCorp, Texas, USA).

\section{Results}

Table 1 shows the baseline characteristics of the study participants at the age of 40 years, groups according to their FPG levels. Among the 901 non-diabetic individuals, the proportions of those with an FPG of $110-125 \mathrm{mg} / \mathrm{dL}$ and those with an FPG of 100-109 mg/dL were 4.7\% (43 subjects) and $21.5 \%$ (194 subjects). The FPG levels increased with BMI, systolic blood pressure, diastolic blood pressure, total cholesterol, and triglycerides.

During a median follow-up period of 12.0 years (7.0 years in incident diabetes cases), a total of 87 incident diabetes cases were reported, yielding 10,228 person-years (Table 2).

The Kaplan-Meier curve shows that individuals with increased FPG levels have higher incidence rates of diabetes. The log rank test gave $\mathrm{p}<0.001$ (Figure). The 10-year cumulative incidence of diabetes increased with FPG levels, with percentages of $1.9 \%$ (FPG of $<90 \mathrm{mg} / \mathrm{dL}$ ), 3.2\% (FPG of 90-99 mg/dL), $14.7 \%$ (FPG of 100-109 mg/dL) and $48.9 \%$ (FPG of 110-125 mg/dL) of subjects developing diabetes (Table 2).

Table 3 displays the HRs of developing diabetes. In the multivariate model, individuals with an FPG of 100-109 mg/ $\mathrm{dL}$ and $110-125 \mathrm{mg} / \mathrm{dL}$ had an increased risk for developing diabetes, with HRs of 5.2 [95\% Confidence Interval $(\mathrm{CI})=$ 2.4-11.2] and 21.3 (95\% $\mathrm{CI}=9.2-49.5)$, respectively, relative to those with an FPG of $<90 \mathrm{mg} / \mathrm{dL}$. On the other hand, 
Table 1. Baseline Characteristics according to FPG Levels at the Age of 40

\begin{tabular}{|c|c|c|c|c|c|c|c|c|c|}
\hline \multirow[t]{2}{*}{ FPG $(n$} & \multicolumn{2}{|r|}{$<90$} & \multicolumn{2}{|c|}{$90-99$} & \multicolumn{2}{|c|}{$100-109$} & \multicolumn{2}{|c|}{$110-125$} & \multirow{2}{*}{$\begin{array}{l}\text { Overall } \\
\text { ANOVA } \\
\text { p value }\end{array}$} \\
\hline & 258 & $(28.6 \%)$ & 406 & $(45.1 \%)$ & 194 & $(21.5 \%)$ & 43 & $(4.7 \%)$ & \\
\hline BMI $(\mathrm{kg} / \mathrm{m} 2)$ & 23.6 & $(23.2-23.9)$ & 23.8 & $(23.6-24.1)$ & 24.9 & $(24.4-25.3)$ & 24.8 & $(23.8-25.7)$ & $<0.001$ \\
\hline Systolic blood pressure (mmHg) & 117 & $(115-118)$ & 117 & $(116-118)$ & 122 & $(120-124)$ & 125 & $(120-129)$ & $<0.001$ \\
\hline Diastolic blood pressure $(\mathrm{mmHg})$ & 76 & $(75-77)$ & 77 & $(76-78)$ & 80 & $(79-82)$ & 83 & $(80-86)$ & $<0.001$ \\
\hline Total Cholesterol (mg/dL) & 194 & $(190-198)$ & 197 & $(194-201)$ & 208 & $(203-213)$ & 213 & $(204-224)$ & $<0.001$ \\
\hline HDL Cholesterol (mg/dL) & 53 & $(51-54)$ & 52 & $(51-54)$ & 52 & $(50-55)$ & 48 & $(45-52)$ & 0.421 \\
\hline Triglycerides $(\mathrm{mg} / \mathrm{dL})^{\mathrm{a}}$ & 107 & $(100-115)$ & 113 & $(107-120)$ & 135 & $(125-147)$ & 179 & $(148-217)$ & $<0.001$ \\
\hline
\end{tabular}

Data are $\mathrm{n}(\%)$ or mean $(95 \% \mathrm{CI})$.

${ }^{a}$ Geometric mean

ANOVA: analysis of variance, BMI: body mass index, CI: confidence interval, FPG: fasting plasma glucose, HDL: high-density lipoprotein

Table 2. Incidence of Diabetes according to FPG Levels at the Age of 40

\begin{tabular}{lcccccc}
\hline \multicolumn{1}{c}{ FPG categories (mg/dL) } & $n$ & $\begin{array}{c}\text { Number of } \\
\text { incident cases }\end{array}$ & $\begin{array}{c}\text { Time at risk } \\
\text { (person-years) }\end{array}$ & $\begin{array}{c}\text { Incidence rate } \\
\text { (per 1,000 } \\
\text { person-year) }\end{array}$ & $\begin{array}{c}\text { 10-year } \\
\text { cumulative } \\
\text { incidence (\%) }\end{array}$ & $(95 \% \mathrm{CI})$ \\
\hline$<90$ & 258 & 8 & 3,021 & 2.6 & 1.9 & $(0.7-5.0)$ \\
$90-99$ & 406 & 21 & 4,681 & 4.5 & 3.2 & $(1.8-5.8)$ \\
$100-109$ (High-normal) & 194 & 37 & 2,179 & 17.0 & 14.7 & $(10.3-20.9)$ \\
$110-125$ (IFG) & 43 & 21 & 347 & 60.4 & 48.9 & $(34.8-65.4)$ \\
Total & 901 & 87 & 10,228 & 8.5 & 7.6 & $(6.0-9.7)$ \\
\hline
\end{tabular}

CI: confidence interval, FPG: fasting plasma glucose, IFG: impaired fasting glucose

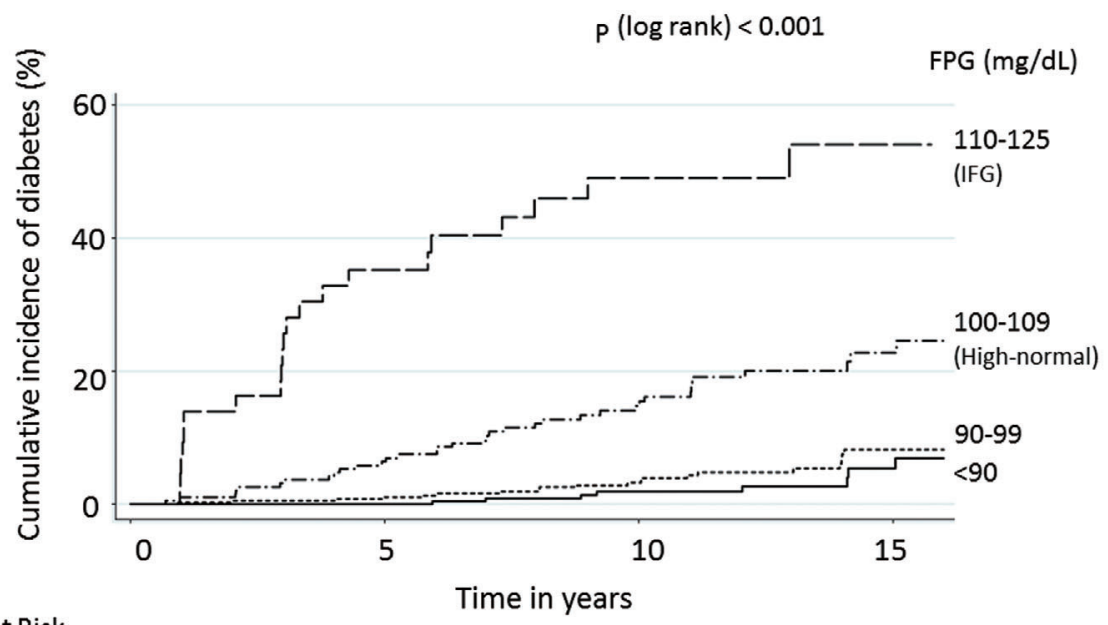

\section{No. at Risk}

Time in years

$\begin{array}{lllllc}\text { FPG: }<90 & \mathrm{mg} / \mathrm{dL} & 258 & 237 & 181 & 62 \\ \text { FPG: } 90-99 & \mathrm{mg} / \mathrm{dL} & 406 & 360 & 264 & 105 \\ \text { FPG: } 100-109 \mathrm{mg} / \mathrm{dL} & 194 & 172 & 124 & 46 \\ \text { FPG: } 110-125 \mathrm{mg} / \mathrm{dL} & 43 & 27 & 16 & 10\end{array}$

Figure. Kaplan-Meier curve estimates of developing diabetes according to FPG levels at the Age of 40.

those with an FPG of 90-99 $\mathrm{mg} / \mathrm{dL}$ had a non-significant increased risk, with a HR of $1.6(95 \% \mathrm{CI}=0.7-3.5)$. A positive trend between the FPG levels and the risk for developing diabetes was also observed ( $\mathrm{p}$ for trend $<0.001$ ). Based on these HRs in combination with the distribution of the FPG, the PAF of an FPG of $90 \mathrm{mg} / \mathrm{dL}$ or more for incident diabetes was $68.0 \%$ compared with an FPG of $<90 \mathrm{mg} / \mathrm{dL}$. The PAFs of the FPG of $90-99 \mathrm{mg} / \mathrm{dL}, 100-109 \mathrm{mg} / \mathrm{dL}$ and $110-$ 
Intern Med 51: 2703-2708, 2012 DOI: 10.2169/internalmedicine.51.7926

Table 3. HRs of Developing Diabetes according to FPG Levels at the Age of 40

\begin{tabular}{|c|c|c|c|c|c|}
\hline FPG categories (mg/dL) & $\begin{array}{c}\text { Crude } \\
\text { HR }\end{array}$ & $(95 \% \mathrm{CI})$ & $\begin{array}{c}\text { Adjusted } \\
\mathrm{HR}^{\mathrm{a}}\end{array}$ & $(95 \% \mathrm{CI})$ & $\mathrm{p}$ for trend \\
\hline$<90$ & 1.0 & reference & 1.0 & reference & $<0.001$ \\
\hline $90-99$ & 1.7 & $(0.7-3.8)$ & 1.6 & $(0.7-3.5)$ & \\
\hline $100-109$ (High -normal) & 6.4 & $(3.0-13.7)$ & 5.2 & $(2.4-11.2)$ & \\
\hline $110-125$ (IFG) & 23.7 & $(10.5-53.7)$ & 21.3 & $(9.2-49.5)$ & \\
\hline
\end{tabular}

adjusted for BMI, systolic blood pressure, total cholesterol, and triglyceride.

BMI: body mass index, CI: confidence interval, FPG: fasting plasma glucose, HR: hazard ratio, IFG: impaired fasting glucose

Table 4. Studies on the Risk for Developing Diabetes among Individuals with High-Normal Glycaemia

\begin{tabular}{|c|c|c|c|c|c|c|}
\hline Study & Cohort selection & $\begin{array}{l}\text { Sample size } \\
\qquad \mathrm{M} / \mathrm{F}\end{array}$ & $\begin{array}{l}\text { Age at } \\
\text { baseline } \\
\text { (years) }\end{array}$ & $\begin{array}{l}\text { Follow- } \\
\text { up } \\
\text { (years) }\end{array}$ & $\begin{array}{c}\text { FPG } \\
\text { category of } \\
\text { interest } \\
(\mathrm{mg} / \mathrm{dL})\end{array}$ & $\begin{array}{c}\text { Incidence rate } \\
\text { of diabetes } \\
\text { (per } 1,000 \text { person-years) }\end{array}$ \\
\hline $\begin{array}{l}\text { Qiao et al, } \\
2003 \text { (4) }\end{array}$ & $\begin{array}{l}\text { Persons from general } \\
\text { population in Finland }\end{array}$ & $\begin{array}{c}3,404 \\
(1,654 / 1,750)\end{array}$ & $45-64$ & 10 & 98-109 & 5 \\
\hline $\begin{array}{l}\text { Balkau et al, } \\
2005 \text { (12) }\end{array}$ & $\begin{array}{l}\text { Persons participating } \\
\text { in the French } \\
\text { D.E.S.I.R. study }\end{array}$ & $\begin{array}{c}4,452 \\
(2,176 / 2,276)\end{array}$ & $30-64$ & 6 & 100-109 & 6 \\
\hline $\begin{array}{l}\text { Ryu et al, } \\
2006 \text { (13) }\end{array}$ & $\begin{array}{l}\text { Workplace employees } \\
\text { in Korea }\end{array}$ & $\begin{array}{c}13,189 \\
(15,079 / 0)\end{array}$ & $30-59$ & 4 & $100-109$ & 13 \\
\hline $\begin{array}{l}\text { Kato et al, } \\
2009 \text { (7) }\end{array}$ & $\begin{array}{l}\text { Persons from general } \\
\text { population in Omiya, } \\
\text { Japan }\end{array}$ & $\begin{array}{c}11,369 \\
(3,315 / 8,054)\end{array}$ & $62 \pm 6$ & 7 & $\begin{array}{l}100-104 \\
105-109\end{array}$ & $\begin{array}{l}16 \\
30\end{array}$ \\
\hline $\begin{array}{l}\text { Noda et al, } \\
2010(8)\end{array}$ & $\begin{array}{l}\text { Persons from general } \\
\text { population in several } \\
\text { cities, Japan }\end{array}$ & $\begin{array}{c}2,207 \\
(821 / 1,386)\end{array}$ & $62 \pm 5$ & 5 & $\begin{array}{l}100-104 \\
105-109\end{array}$ & $\begin{array}{l}12 \\
30\end{array}$ \\
\hline $\begin{array}{l}\text { Oizumi et al, } \\
2011 \text { (9) }\end{array}$ & $\begin{array}{l}\text { Persons from general } \\
\text { population in } \\
\text { Funagata, Japan }\end{array}$ & $\begin{array}{c}3,413 \\
(1,516 / 1,897)\end{array}$ & $56 \pm 12$ & 12 & $101-105$ & 18 \\
\hline $\begin{array}{l}\text { The present } \\
\text { study }\end{array}$ & $\begin{array}{l}\text { Workplace employees } \\
\text { in Japan }\end{array}$ & $\begin{array}{c}901 \\
(901 / 0)\end{array}$ & 40 & 12 & $\begin{array}{l}100-104 \\
105-109 \\
100-109 \\
\end{array}$ & $\begin{array}{l}16 \\
19 \\
17\end{array}$ \\
\hline
\end{tabular}

$125 \mathrm{mg} / \mathrm{dL}$ were $8.2 \%, 28.7 \%$ and $31.1 \%$, respectively.

\section{Discussion}

The aim of the present study was to examine the risk for developing diabetes among individuals with high-normal glycemia at the age of 40 . As mentioned previously, an increased number of people have been diagnosed to have this condition after the implementation of the annual special health screening system in Japan. However, a realistic risk estimate of developing diabetes among the early middleaged population is lacking. The novelty of the present study was that we followed a cohort of subjects who were all 40 years of age at baseline for more than 10 years and showed a pragmatic risk estimate. We demonstrated that the 10-year cumulative incidence of diabetes among those with highnormal glycemia was approximately $15 \%$, which was significantly associated with a 5 -fold increase in the risk for future diabetes compared to those with an FPG of $<90 \mathrm{mg} / \mathrm{dL}$. Compared with other studies reporting the incidence rate of diabetes among individuals with high-normal glycemia (Table 4), our study showed a consistent result with the studies conducted in Japan and Korea $(7-9,13)$. Although the average age of participants in each study varied, individuals with high-normal glycemia had a similar incidence of diabetes. This means that high-normal glycemia might be a risk factor for future diabetes, regardless of age. On the other hand, studies performed in European populations $(4,12)$ have re- 
ported a lower incidence of diabetes than those in Japan and Korea. This finding suggests that ethnic differences, which might reflect differences in physical traits or lifestyle choices, could modify the association between the FPG and the risk for future diabetes.

Regarding the relationship between the baseline FPG levels and the risk for future diabetes, a positive and continuous association was observed. In terms of the relative risk for future diabetes, the subjects with IFG had a much higher risk than those with high-normal glycemia. However, as shown in the PAFs, the importance of high-normal glycemia is not negligible. In the present study, the prevalence of high-normal glycemia was higher than that of IFG $(21.5 \%$ vs. $4.7 \%$ ). Therefore, if the 10 -year cumulative incidence of diabetes in the corresponding categories $(15 \%$ in those with high-normal glycemia and $49 \%$ in those with IFG) were applied to the prevalence, the absolute number of incident diabetes cases in 10 years would be larger in those with highnormal glycemia than in those with IFG. In fact, incident diabetes cases were most frequently observed in the baseline high-normal FPG category (Table 2). Similar findings were also observed in other studies $(8,9)$.

In the special health counseling system (tokutei hoken shidou), health guidance on lifestyle modification is provided to those at high-risk for metabolic syndrome. In terms of the FPG levels, not only those with IFG, but also those highnormal glycemia are considered to be high-risk individuals, which seems rational considering the number of diabetes cases arising from the FPG category of high-normal glycemia.

There are several limitations that should be considered when interpreting the results of the present study. First, the definition of diabetes in the present study was based on a single measurement of FPG or self-reporting, which may involve misclassification. Our definition could also miss those who would have been diagnosed as diabetics if a 2-hour value of the oral glucose tolerance test (OGTT) was available. Although the OGTT is a standard diagnostic method, it is impractical to perform the test for the annual health checkup. In practice, it will be easier and more appropriate to estimate the risk for future diabetes using the FPG without knowing the 2-hour value. Second, there might have been heterogeneity in the cohort because of the long entry period. The study participants were born between 1949 and 1960, a period during which Japanese society changed dramatically in terms of nutrition and public hygiene. Such changes may have had an influence on the incidence of diabetes. To address this point, we further examined the incidence, dividing the cohort into two groups according to their birth years. No significant difference was found in the incidence of diabetes between those born in earlier years and those born later ( $p$ for $\log$ rank=0.965). Although no difference was observed, the long entry period may have affected how representative the study participants, current earlymiddle-aged Japanese businessmen, were of the general population. Third, those who did not undergo the health checkup annually might have brought a bias to the study, which could have led to the underestimation of the cumulative incidence of diabetes. In a total of 87 incident diabetes cases, 14 cases were diagnosed with diabetes after over one year had passed since the previous checkup. If they had not skipped the annual checkup, diabetes would have been diagnosed earlier. Fourth, there could be an issue of generalizability since the study participants were restricted to men. We also analyzed the data on female employees. No effect modification by gender on the association between the FPG levels and the risk for future diabetes was observed (data not shown). However, the number of female employees and incident diabetes cases in females during the same follow-up period was too small to conduct an adequate statistical analysis. Further research is therefore required to confirm the risk in females. Finally, it remains unknown whether the health advice given to those with high-normal glycemia and IFG modulated their risk for future diabetes, which would lead to an underestimation of the result.

In summary, the present study showed that individuals with high-normal glycemia at the age of 40 had a significant increase in their risk for future diabetes. From the perspective of an individual's risk perception, high-normal glycemia without any symptoms may not be considered a serious condition. However, from the viewpoint of public health, the impact of those with high-normal glycemia on the incidence of future diabetes seems to be considerable. The results of the present study provide practical information on the risk for future diabetes, which enables individuals with highnormal glycemia to perceive their risk more realistically. As a next step, an early intervention program directed toward these patients is key for preventing future diabetes.

The authors state that they have no Conflict of Interest (COI).

\section{References}

1. Report of the expert committee on the diagnosis and classification of diabetes mellitus. Diabetes Care 26 (Suppl 1): S5-S20, 2003.

2. Kuzuya T, Nakagawa S, Satoh J, et al. Report of the Committee on the classification and diagnostic criteria of diabetes mellitus. Diabetes Res Clin Pract 55: 65-85, 2002.

3. Forouhi NG, Balkau B, Borch-Johnsen K, et al. The threshold for diagnosing impaired fasting glucose: a position statement by the European Diabetes Epidemiology Group. Diabetologia 49: 822827, 2006.

4. Qiao Q, Lindstrom J, Valle TT, Tuomilehto J. Progression to clinically diagnosed and treated diabetes from impaired glucose tolerance and impaired fasting glycaemia. Diabet Med 20: 1027-1033, 2003.

5. Wang JJ, Yuan SY, Zhu LX, et al. Effects of impaired fasting glucose and impaired glucose tolerance on predicting incident type 2 diabetes in a Chinese population with high post-prandial glucose. Diabetes Res Clin Pract 66: 183-191, 2004.

6. Tai ES, Goh SY, Lee JJ, et al. Lowering the criterion for impaired fasting glucose: impact on disease prevalence and associated risk of diabetes and ischemic heart disease. Diabetes Care 27: 17281734, 2004.

7. Kato M, Noda M, Suga H, Matsumoto M, Kanazawa Y. Fasting 
plasma glucose and incidence of diabetes --- implication for the threshold for impaired fasting glucose: results from the population-based Omiya MA cohort study. J Atheroscler Thromb 16: $857-861,2009$.

8. Noda M, Kato M, Takahashi Y, et al. Fasting plasma glucose and 5 -year incidence of diabetes in the JPHC diabetes study: suggestion for the threshold for impaired fasting glucose among Japanese. Endocr J 57: 629-637, 2010.

9. Oizumi T, Daimon M, Karasawa S, et al. Assessment of plasma glucose cutoff values to predict the development of type 2 diabetes in a Japanese sample: the Funagata Study. Diabetol Int 2: 2631, 2011.

10. Kim SH, Shim WS, Kim EA, et al. The effect of lowering the threshold for diagnosis of impaired fasting glucose. Yonsei Med J 49: 217-223, 2008.

11. Wareham NJ, Byrne CD, Williams R, Day NE, Hales CN. Fasting proinsulin concentrations predict the development of type 2 diabe- tes. Diabetes Care 22: 262-270, 1999.

12. Balkau B, Hillier T, Vierron E, et al. Comment to: Borch-Johnsen K, Colagiuri S, Balkau B, et al. (2004) Creating a pandemic of prediabetes: the proposed new diagnostic criteria for impaired fasting glycaemia. Diabetologia 47: 1396-1402. Diabetologia 48: 801802, 2005.

13. Ryu S, Shin H, Chang Y, Sung KC, Song J, Lee SJ. Should the lower limit of impaired fasting glucose be reduced from $110 \mathrm{mg} /$ dL in Korea? Metabolism 55: 489-493, 2006.

14. Ministry of Health, Labour and Welfare. 2008 [cited 2008 17th January]; Available from: http://www.mhlw.go.jp/bunya/ shakaihosho/iryouseido01/dl/info03j-1.pdf

15. Seino Y, Nanjo K, Tajima N, et al. Report of the Committee on the classification and diagnostic criteria of diabetes mellitus. Diabetol Int 1: 2-20, 2010.

16. Rockhill B, Newman B, Weinberg C. Use and misuse of population attributable fractions. Am J Public Health 88: 15-19, 1998.

(C) 2012 The Japanese Society of Internal Medicine http://www.naika.or.jp/imonline/index.html 